\title{
Clinical Utility of Rapid Plasma Neutrophil Gelatinase- Associated Lipocalin Assays for Diagnosing Acute Kidney Injury in Critically Ill Newborn Infants
}

Lindsey Yoojin Chung, Won Sik Choi, Eui Kyung Choi, Jeonghee Shin, Hyung Eun Yim, and Byung Min Choi Department of Pediatrics, Korea University College of Medicine, Seoul, Korea

\section{ABSTRACT}

Purpose: Neutrophil gelatinase-associated lipocalin (NGAL) has been identified as an early marker of acute kidney injury (AKI). This study was designed to evaluate the clinical utility of the rapid plasma NGAL assay for diagnosing AKI in critically ill new. born infants in the neonatal intensive care unit (NICU).

Methods: The medical records of 178 critically ill newborn infants $>34$ weeks of gestational age who underwent plasma NGAL measurement during the first week of life in the Korea University Ansan Hospital NICU from February 2011 to August 2015 were retrospectively reviewed. Plasma NGAL levels were measured at bedside by using a commercial competitive immunoassay kit simultaneously with serum creatinine $(\mathrm{Cr})$ level determination.

Results: Of 178 newborn infants enrolled in this study (study group), 25 infants had AKI (AKI group) while 153 infants had no AKI (control group). The plasma NGAL level in the AKI group (114.0 [76.5-281.5] ng/mL) was significantly higher than that in the control group (74.0 [52.5-122.5] ng/mL, $P=0.001)$. Moreover, plasma NGAL levels were found to be correlated with serum $\mathrm{Cr}$ levels in the study group $(r=0.208, P=$ 0.005). Plasma NGAL achieved an area under the receiver operating characteristic curve of 0.705 for detecting AKI (95\% confidence interval: 0.593-0.817). The best cutoff plasma NGAL level for AKI diagnosis was $100 \mathrm{ng} / \mathrm{mL}$.

Conclusion: The rapid plasma NGAL assay has diagnostic value for AKI in critically ill newborn infants $>34$ weeks of gestational age. Further investigations with a larger population are needed to confirm the potential use of plasma NGAL levels for diagnosing AKI in newborn infants.

Key Words: Neutrophil gelatinase-associated lipocalin, Acute kidney injury, Serum creatinine, Newborn infants

\section{INTRODUCTION}

Acute kidney injury (AKI) is a serious condition that damages the tubular function of the
Received: 19 September 2017

Revised: 24 October 2017

Accepted: 24 October 2017

Correspondence to: Byung Min Choi

Department of Pediatrics, Korea

University Ansan Hospital, 123,

Jeokgeum-ro, Danwon-gu, Ansan

15355 , Korea

Tel: +82-31-412-6557

Fax: +82-31-405-8591

E-mail: cbmin@korea.ac.kr

Copyright(c)

By Korean Society of Neonatology.

All right reserved.

This is an Open-Access article distributed under the terms of the Creative Commons Attribution Non-Commercial License (http://creativecommons.org/licenses/ by-nc/4.0), which permits unrestricted non-commercial use, distribution, and reproduction in any medium, provided the original work is properly cited. 
kidney ${ }^{1)}$. It is frequently found in infants in the neonatal intensive care unit (NICU), with poor outcome associated with increased length of stay and mortality ${ }^{2)}$. Critically ill infants in the NICU are at a high risk of having AKI because they have multiple risk factors $^{3-5)}$.

Current studies have shown that serum creatinine (Cr) level is widely used for diagnosing neonatal $\mathrm{AKI}^{6,7)}$; however, it has many disadvantages. For example, serum Cr levels can vary depending on age, gender, muscle mass, medication, and intravascular volume status ${ }^{8)}$. Furthermore, elevation of serum Cr level is not a marker but a consequence of kidney injury. It is not present in patients before $25-50 \%$ loss of kidney function. The unique renal physiology of preterm and term infants, associated with renal immaturity, also creates challenges for using serum $\mathrm{Cr}$ level as an AKI marker ${ }^{9)}$. Furthermore, in the first few days of life, serum $\mathrm{Cr}$ reflects the maternal value. It differs widely depending on weight and gestational age ${ }^{10,11)}$. Therefore, novel neonatal AKI criteria with new biomarker need to be established owing to the possibility of delayed diagnosis and misclassification of AKI by using serum Cr levels. As a result, a significant amount of research has been conducted to identify novel biomarkers of damage to allow for the earlier identification of neonates with AKI. These novel biomarkers include neutrophil gelatinase-associated lipocalin (NGAL), cystatin C, kidney injury molecule-1, and others ${ }^{12-15)}$.

NGAL, a $25-\mathrm{kD}$ protein of the lipocalin superfamily, is a promising early biomarker of AKI. It is released in kidney tissue and upregulated in kidney tubule cells. In addition, renal expression of NGAL is increased dramatically after renal ischemia ${ }^{16)}$. The NGAL concentration in blood has been demonstrated to be a sensitive and specific early marker of $\mathrm{AK}^{17}{ }^{17}$. In addition, it is useful for heterogeneous groups of children and adults ${ }^{18,19)}$. Serum and urine NGAL levels have also shown good performance in newborn infants with $\mathrm{AKI}^{13,20,21)}$.

In infants, using urine samples for NGAL measurement has a limitation because collecting urine for AKI evaluation is difficult owing to anuria, oliguria, or impaired urine-concentrating ability in infants ${ }^{8)}$. To overcome such limitation in collecting urine sample, studies using blood NGAL measurement have been performed for several neonatal groups ${ }^{13,17,22)}$. Recently, rapid plasma NGAL assay has provided clinicians an opportunity to explore its potential usefulness at bedside within $20 \mathrm{~min}$. Therefore, the objective of this study was to evaluate the clinical utility of the rapid plasma NGAL assay for diagnosing AKI in critically ill new. born infants $>34$ weeks of gestational age.

\section{MATERIALS AND METHODS}

\section{Study population}

This study was performed retrospectively by reviewing the medical records of critically ill newborn infants admitted to the NICU of Korea University Ansan Hospital between February 2011 and August 2015. During the study period, 178 critically ill newborn infants $>34$ weeks of gestational age who underwent plasma NGAL measurement during the first week of life were enrolled.

Measurement of plasma NGAL was performed simultaneously with serum Cr level determination for critically ill newborn infants with a high risk of having AKI owing to their multiple risk factors. The study group comprising 178 newborn infants was divided into two groups according to the AKI criteria, as follows: 1) infants with AKI (AKI group) and 2) infants without AKI (control group). This study was approved by the Institutional Review Board (IRB) of Korea University Ansan Hospital (IRB no.: AS17137).

\section{Diagnosis and staging of AKI}

The diagnosis of AKI was based on serum $\mathrm{Cr} \geq 1.5 \mathrm{mg} / \mathrm{dL}$ on the first week of life (normal renal function in the mother of the neonate) or on the neonatal modified Kidney Disease: Improv ing Global Outcome (KDIGO) Cr criteria during the first week of life ${ }^{7,23,24)}$. The neonatal modified KDIGO Cr criteria are as follows:

- Stage I AKI was diagnosed when the serum $\mathrm{Cr}$ level increased by $\geq 0.3 \mathrm{mg} / \mathrm{dL}$ within $48 \mathrm{~h}$ or the serum Cr level increased by $\geq 1.5-1.9 \times$ the reference level (lowest previous serum $\mathrm{Cr}$ value) within 7 days.

- Stage II AKI was diagnosed when the serum Cr level in creased by $\geq 2.0-2.9 \times$ the reference level.

- Stage III AKI was diagnosed when the serum Cr increased by $\geq 3 \times$ the reference serum $\mathrm{Cr}$, or when the serum $\mathrm{Cr}$ level was $\geq 2.5 \mathrm{mg} / \mathrm{dL}$, or when the infant was receiving dialysis.

\section{Measurement of plasma NGAL}

Plasma NGAL levels were measured with a commercial competitive immunoassay kit (Alere Triage ${ }^{\circledR}$ NGAL test; Alere Inc., San Diego, CA, USA) at bedside. The assay has a detection range of $60-1,300 \mathrm{ng} / \mathrm{mL}$ with a coefficient of variation of $10-15 \%$. All samples were simultaneously tested once the sampling was completed, including plasma NGAL level, serum Cr level, and other routine tests. 


\section{Clinical data collection}

Maternal and neonatal data were collected from medical records through a retrospective review. The collected data included gestational age, birth weight, height, gender, Apgar score (at 1 and $5 \mathrm{~min}$ ), antenatal steroid administration, mode of delivery, and maternal pregnancy complications. Neonatal outcomes were also collected, including perinatal asphyxia, persistent pulmonary hypertension of the newborn (PPHN), respiratory distress syndrome (RDS), meconium aspiration syndrome (MAS), patent ductus arteriosus (PDA), neonatal sepsis, necrotizing enterocolitis (NEC), intraventricular hemorrhage (IVH), periventricular leu komalacia (PVL), and mortality. Patients with congenital renal abnormalities detected with abdominal ultrasound were excluded. The definitions of neonatal outcomes in this study are as follows:

- Perinatal asphyxia was defined as $\mathrm{pH}<7.2$ and Apgar score $\leq 7$ at 5 minutes of the infants at birth.

$\circ$ PPHN was defined as the need for nitric oxide treatment for infants with ventilator care.

- RDS was defined as infants the need for intratracheal surfactant instillation.

- MAS was defined as meconium aspiration and requirement for ventilator care.

- PDA was defined as two-dimensional echocardiogramproven PDA treated with ibuprofen.

- Sepsis was defined as pathogen-proven sepsis.

- NEC was evaluated using abdominal radiography and physical examination, and defined as stage II and stage III of the modified Bell's staging criteria.

- IVH was defined as a Papile-Burstein classification grade of II or higher.

○ PVL was defined by brain sonography-proven PVL.

Clinical laboratory results such as serum Cr level, white blood cell (WBC) count, platelet count, and C-reactive protein (CRP) level were recorded for each infant as part of routine care. Leukocytosis was defined as WBC count $>21,000 / \mathrm{mm}^{3}$. CRP positivity was defined as CRP level $>0.5 \mathrm{mg} / \mathrm{dL}$. Urine output was recorded during the first week of life. Urine output of $<0.5 \mathrm{~mL} \cdot \mathrm{kg}^{-1}$. hour ${ }^{-1}$ indicated oliguria. In the AKI group, the test results of plasma NGAL and serum Cr levels were used at the time of AKI diagnosis.

\section{Statistical analysis}

Categorical variables are expressed as number (percentage), whereas continuous variables are expressed as mean \pm standard deviation or median [25th-75th percentile]. Continuous variables between two groups were compared with Mann-Whitney's rank sum $U$ test. Categorical variables were compared with Pearson's chi-square test or Fisher's exact test as appropriate. Correlations between plasma NGAL and serum Cr levels were analyzed using Spearman's rank correlation analysis. Receiver operator characteristic (ROC) analysis was performed to determine the best cutoff value for plasma NGAL level to detect neonatal AKI and assess discrimination ability (by calculating the area under the ROC curve [AUC]) of plasma NGAL to recognize infants with AKI. The cutoff value was estimated using the Youden index (J=sensitivity+specificity-1), with the two righthand quantities being sensitivity and specificity. Statistical analysis was performed using IBM SPSS Statistics version 20.0 for Windows (IBM Corp., Armonk, NY, USA). A $P$-value of $<0.05$ was considered statistically significant.

\section{RESULTS}

Of the 178 infants (study group), 25 infants fulfilled the criteria for AKI (AKI group). A total of 12 infants had serum Cr level $\geq 1.5 \mathrm{mg} / \mathrm{dL}$ ( 2 on the first day of life, 7 on the second day, 1 on the third day, 1 on the fourth day, and 1 on the sixth day of life). On the other hand, 23 infants developed AKI according to the modified neonatal KDIGO Cr criteria (2 on the first day of life, 16 on the second day, 3 on the third day, 1 on the fourth day, and 1 on the sixth day of life). All these 23 infants were classified as having stage I AKI according to the modified neonatal KDIGO Cr criteria. Ten infants fulfilled both criteria (serum $\mathrm{Cr} \geq 1.5 \mathrm{mg} / \mathrm{dL}$ and neonatal modified KIDGO Cr criteria). The remaining 153 infants did not meet the criteria for AKI (control group).

The demographic and clinical characteristics of these two groups are summarized in Table 1 . The gestational age at birth was $36.9 \pm 2.2$ weeks in the AKI group and $37.3 \pm 2.1$ weeks in the control group, with no significant difference between the two groups. The birth weight was $2,533 \pm 695 \mathrm{~g}$ in the AKI group and $2,890 \pm 641 \mathrm{~g}$ in the control group. The height was $46.6 \pm 4.4 \mathrm{~cm}$ in the AKI group and $48.3 \pm 3.6 \mathrm{~cm}$ in the control group. Both birth weight and height were significantly different between the two groups. Birth weight, height, and Apgar scores (at 1 and 5 min) were significantly different between the two groups. However, there were no significant differences in gestational age or small for gestational age (SGA) status between the two groups. A 
Table 1. Demographic and Clinical Characteristics of Infants in the Acute Kidney Injury Group and the Control Group

\begin{tabular}{|c|c|c|c|}
\hline & $\begin{array}{c}\text { AKI } \\
\text { group } \\
(\mathrm{N}=25)\end{array}$ & $\begin{array}{c}\text { Control } \\
\text { group } \\
(\mathrm{N}=153)\end{array}$ & $\begin{array}{c}P \text { - } \\
\text { value }\end{array}$ \\
\hline Gestational age (wks) & $36.9 \pm 2.2$ & $37.3 \pm 2.1$ & 0.345 \\
\hline Birth weight (g) & $2,533 \pm 695$ & $2,890 \pm 641$ & 0.011 \\
\hline Height (cm) & $46.6 \pm 4.4$ & $48.3 \pm 3.6$ & 0.037 \\
\hline Gender (male) & $15(60.0 \%)$ & $90(58.8 \%)$ & 1.000 \\
\hline \multicolumn{4}{|l|}{ Perinatal characteristics } \\
\hline Apgar score, $1 \mathrm{~min}$ & $5[2-6]$ & $8[7-9]$ & $<0.001$ \\
\hline Apgar score, $5 \mathrm{~min}$ & $7[6-8]$ & $9[8-9]$ & $<0.001$ \\
\hline Antenatal steroid administration & $2(8.0 \%)$ & $8(5.2 \%)$ & 0.929 \\
\hline Caesarean section & $18(72.0 \%)$ & $107(70.4 \%)$ & 1.000 \\
\hline Small for gestational age & $6(24.0 \%)$ & $15(9.9 \%)$ & 0.091 \\
\hline \multicolumn{4}{|l|}{ Maternal characteristics } \\
\hline Chorioamnionitis & $1(4.0 \%)$ & $0(0.0 \%)$ & 0.299 \\
\hline Gestational diabetes mellitus & $2(8.0 \%)$ & $9(5.9 \%)$ & 1.000 \\
\hline Pregnancy-induced hypertension & $3(12.0 \%)$ & $9(5.9 \%)$ & 0.483 \\
\hline Preeclampsia & $0(0.0 \%)$ & $3(2.0 \%)$ & 1.000 \\
\hline \multicolumn{4}{|l|}{ Neonatal outcomes } \\
\hline Perinatal asphyxia & $11(32.0 \%)$ & $15(6.5 \%)$ & $<0.001$ \\
\hline $\begin{array}{l}\text { Persistent pulmonary hyperten- } \\
\text { sion of the newborn }\end{array}$ & $2(8.0 \%)$ & $5(3.3 \%)$ & 0.566 \\
\hline Respiratory distress syndrome & $5(20.0 \%)$ & $27(17.6 \%)$ & 0.997 \\
\hline Meconium aspiration syndrome & $4(16.0 \%)$ & $11(7.2 \%)$ & 0.279 \\
\hline Patent ductus arteriosus & $5(20.0 \%)$ & $20(13.1 \%)$ & 0.539 \\
\hline Sepsis & $1(4.2 \%)$ & $1(0.7 \%)$ & 0.635 \\
\hline Necrotizing enterocolitis & $0(0 \%)$ & $0(0 \%)$ & N/A \\
\hline Intraventricular hemorrhage & $1(4.0 \%)$ & $6(3.9 \%)$ & 1.000 \\
\hline Periventricular leukomalacia & $1(4.2 \%)$ & $1(0.7 \%)$ & 0.635 \\
\hline Mortality & $2(8.0 \%)$ & $2(1.3 \%)$ & 0.172 \\
\hline Oliguria & $3(12.0 \%)$ & $0(0.0 \%)$ & 0.002 \\
\hline
\end{tabular}

Categorical variables are expressed as number (in percentages) while continuous variables are expressed as mean \pm standard deviation or median [25th-75th percentile].

Abbreviation: AKI, acute kidney injury.

greater proportion of SGA infants were identified in the AKI group than in the control group; however, the difference was not statistically significant.

In neonatal outcomes, the incidence of perinatal asphyxia was higher $(P<0.001)$ in the AKI group than in the control group. Oliguria only appeared in the AKI group $(P=0.002)$. However, there were no difference in other characteristics or neonatal outcomes between the two groups.

The incidence of leukocytosis or CRP elevation showed no significant difference between the AKI group and the control
Table 2. Laboratory Findings of Infant in the Acute Kidney Injury Group and the Control Group

\begin{tabular}{lccc}
\hline & $\begin{array}{c}\text { AKI group } \\
(\mathrm{N}=25)\end{array}$ & $\begin{array}{c}\text { Control group } \\
(\mathrm{N}=153)\end{array}$ & $\begin{array}{c}P \text { - } \\
\text { value }\end{array}$ \\
\hline Age at exam $(\mathrm{d})$ & $2[2-2]$ & $2[1-2]$ & 0.059 \\
WBC $\left(/ \mathrm{mm}^{3}\right)$ & $23,254 \pm 29,210$ & $17,178 \pm 8,575$ & 0.312 \\
Leukocytosis & $9(36.0 \%)$ & $37(24.2 \%)$ & 0.211 \\
$\quad\left(>21,000 / \mathrm{mm}^{3}\right)$ & & & \\
Platelet $\left(/ \mathrm{mm}^{3}\right)$ & $214,040 \pm 85,916$ & $243,529 \pm 69,928$ & 0.060 \\
CRP $\left(\mathrm{mg} / \mathrm{dL}^{3}\right)$ & $0.4 \pm 0.9$ & $0.5 \pm 1.2$ & 0.726 \\
CRP positivity rate & $4(16 \%)$ & $28(18.3 \%)$ & 1.000 \\
$\quad(>0.5 \mathrm{mg} / \mathrm{dL})$ & & & \\
Serum Cr $(\mathrm{mg} / \mathrm{dL})$ & $1.27[1.06-1.70]$ & $0.78[0.60-0.90]$ & $<0.001$ \\
Plasma NGAL $(\mathrm{ng} / \mathrm{mL})$ & $114.0[76.5-281.5]$ & $74.0[52.5-122.5]$ & 0.001 \\
\hline
\end{tabular}

Categorical variables are expressed as number (in percentages) while continuous variables are expressed as mean \pm standard deviation or median [25th-75th percentile].

Abbreviations: AKI, acute kidney injury; WBC, white blood cell; CRP, C-reactive protein; $\mathrm{Cr}$, creatinine; NGAL, neutrophil gelatinase-associated lipocalin.



Figure 1. Serum creatinine versus plasma neutrophil gelatinase-associated lipocalin levels in the study group. Abbrevia tions: NGAL, neutrophil gelatinase-associated lipocalin; $\mathrm{Cr}$, Creatinine.

group. The median serum $\mathrm{Cr}$ level in the AKI group was significantly higher than that in the control group (1.27 [1.06-1.70] mg/ dL vs. 0.78 [0.60-0.90] mg/dL, $P<0.001)$. The median plasma NGAL level in the AKI group was also significantly higher than that in the control group (114.0 [76.5-281.5] ng/mL vs. 74.0 [52.5122.5] ng/mL, $P=0.001$, Table 2).

The plasma NGAL levels were found to be weakly correlated with serum Cr levels in the study group $(r=0.208, P=0.005$, Figure 1$)$. 


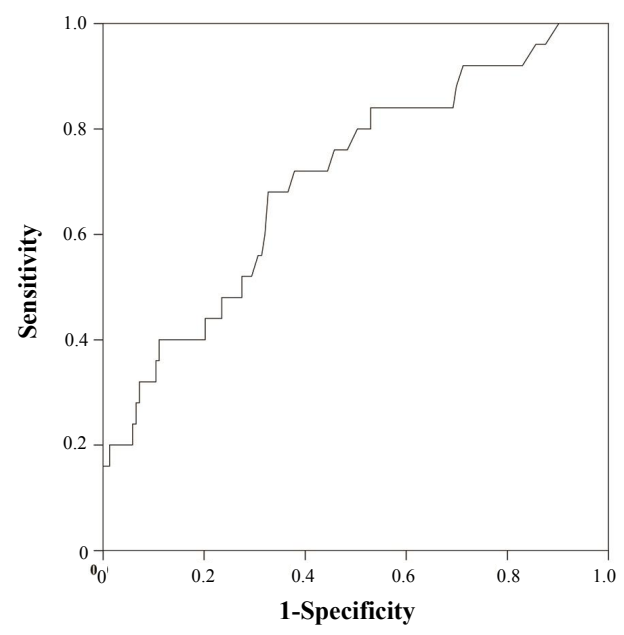

Figure 2. Receiver operating characteristic curve used to determine plasma neutrophil gelatinase-associated lipocalin (plasma NGAL) cutoff value for detecting acute kidney injury. The area under the curve value for plasma NGAL was 0.705 : $95 \%$ confidence interval: $0.593-0.817$ and $P=0.001$.

Table 3. Diagnostic Acuracy of Plasma Neutrophil GelatinaseAssociated Lipocalin Levels for Detecting Acute Kidney Injury According to Various Cutoff Values

\begin{tabular}{lcccc}
\hline $\begin{array}{l}\text { Cutoff value for } \\
\text { plasma NGAL } \\
(\mathrm{ng} / \mathrm{mL})\end{array}$ & $\begin{array}{c}\text { Positive } \\
\text { predictive } \\
\text { value }(\%)\end{array}$ & $\begin{array}{c}\text { Negative } \\
\text { predictive } \\
\text { value }(\%)\end{array}$ & $\begin{array}{c}\text { Sensitivity } \\
(\%)\end{array}$ & $\begin{array}{c}\text { Specificity } \\
(\%)\end{array}$ \\
\hline 70 & 21.2 & 94.9 & 84.0 & 49.0 \\
80 & 20.9 & 92.4 & 72.0 & 55.6 \\
90 & 23.4 & 93.1 & 72.0 & 61.4 \\
100 & 25.0 & 92.7 & 68.0 & 66.7 \\
110 & 22.4 & 90.0 & 52.0 & 70.6
\end{tabular}

Abbreviation: NGAL, neutrophil gelatinase-associated lipocalin.

The AUC for the detection of AKI with plasma NGAL level was 0.705 (95\% confidence interval: $0.593-0.817, P=0.001$, Figure 2). The best cutoff plasma NGAL level for the detection of AKI, estimated using Youden index, was found to be $100 \mathrm{ng} / \mathrm{mL}$. At this cutoff value, the sensitivity was $68.0 \%$, the specificity was $66.7 \%$, and the positive predictive value was $25.0 \%$ (Table 3 ).

\section{DISCUSSION}

Serum Cr level is still widely used in current clinical studies to define neonatal $\mathrm{AKI}^{6,7)}$ despite its limitations of being influenced by maternal-fetal transplacental transfer, body mass, and maturation variability $^{8-11)}$. Furthermore, elevation of serum Cr level is a reflection of decreased renal function, not a marker of kidney injury. It is not appear in patients before $25-50 \%$ loss of kidney function $^{8,11)}$. In addition, it takes time for serum $\mathrm{Cr}$ level changes to be detected after kidney injury, thus limiting its usefulness for early detection of $\mathrm{AKI}^{25,26)}$.

As a novel diagnostic marker for AKI, serum and urine NGAL levels have shown good performance in newborn infants with AKI who undergo cardiopulmonary bypass or those with perinatal asphyxia $^{13,20)}$. Also, elevation of NGAL takes only two hours after kidney injury, while elevation of serum $\mathrm{Cr}$ takes at least one day ${ }^{20,25)}$.

For the last two decades, urine NGAL level has been studied extensively because NGAL is released directly into the urine by kidney tubules after renal injury. However, collecting urine for AKI evaluation is difficult owing to anuria, oliguria, or impaired urine-concentration ability in infants ${ }^{8}$. Considering that urinary NGAL levels are correlated with the plasma or serum levels of NGAL regardless of the cause of increased NGAL production ${ }^{27)}$, many studies have evaluated the value of blood NGAL levels in neonatal groups ${ }^{13,17,22)}$.

This study aimed to assess whether increased plasma NGAL level might be useful as a diagnostic marker of AKI in critically ill newborn infants diagnosed as having AKI based on serum Cr levels. Our results revealed that plasma NGAL levels were increased significantly in the AKI group, suggesting that kidney injury might be a possible cause of elevated plasma NGAL level. Moreover, the AUC was moderately accurate and statistically fair. Therefore, plasma NGAL showed good performance in AKI diagnosis in critically ill newborn infants in the NICU.

Compared with previous studies on newborn infants with AKI $13,17,20,22,28,29)$, our study included a neonatal population in the late preterm period with a gestational age of 34-36 weeks. In addition, the AKI population of our study was composed of infants with mild AKI because all cases were classified as stage I AKI.

The plasma NGAL and serum Cr levels showed weak correlations in the study group $(r=0.208, P=0.005)$. With this tendency, plasma NGAL level might have some relationship with serum $\mathrm{Cr}$ level to be a biomarker for diagnosing AKI. Similarly, in the study of El-Farghali et al. ${ }^{17)}$ on critically ill newborn infants, serum NGAL levels showed a significant correlation with subsequent serum $\mathrm{Cr}$ levels measured within $48 \mathrm{~h}$ after admission $(r=0.78, P=$ $0.0001)^{17)}$. Therefore, plasma NGAL level could be a diagnostic marker comparable to serum Cr level.

Recently, it has been reported that blood NGAL level can help define AKI in various neonatal groups ${ }^{13,17,20,22,28,29)}$. Jiang and Cui ${ }^{28)}$ performed a meta-analysis concerning the accuracy of using 
NGAL level in the diagnosis of AKI to clarify the definition of AKI. The studies included in their meta-analysis used various diagnostic criteria of AKI (serum $\mathrm{Cr} \geq 1.5 \mathrm{mg} / \mathrm{dL}$ or serum $\mathrm{Cr}$ increase from baseline of $>0.3 \mathrm{mg} / \mathrm{dL}$, or both). The results of their bivariate model for diagnostic meta-analysis showed summary AUC, pooled diagnostic odd ratio, pooled sensitivity, and pooled specificity of $0.87,27.20,81 \%$, and $86 \%$ respectively, indicating that NGAL level could be used to diagnose AKI in infants. After the diagnostic meta-analysis, a prospective study on asphyxiated neonates by Baumert et al. ${ }^{29)}$ also showed that serum NGAL level has a high specificity as an AKI marker $(\mathrm{AUC}=0.93, P=0.01$, specificity=95\%).

In our study, the results of statistical analysis showed lower sensitivity, specificity, and AUC compared with those of previous studies ${ }^{13,17,20,22,28,29)}$. This might be because most of the infants with AKI included in our study showed mild disease (stage I). However, in the study of El-Farghali et al. ${ }^{17)}$ which is the only study classified and reported AKI stage, 25 of 34 infants showed stage II or III AKI in the Acute Kidney Injury Network (AKIN) Cr criteria. Their AUC (0.95) was higher than that of the present study. It seems to be owing to the fact that study of El-Farghali et al. contained more infants with high stage of AKI than present study.

In our study, the best cutoff value for plasma NGAL to diagnose AKI was $100 \mathrm{ng} / \mathrm{mL}$, with a sensitivity of $68.0 \%$ and a specificity of $66.7 \%$. The meta-analysis performed by Jiang and Cui ${ }^{28)}$ reported a cutoff value ranging from 66.6 to $157 \mathrm{ng} / \mathrm{mL}$. Baumert et al. ${ }^{29)}$ reported a cutoff value of $140.7 \mathrm{ng} / \mathrm{mL}$ for AKI diagnosis in patients with asphyxia. These differences could be related to the inclusion of late preterm infants between 34 and 36 weeks of gestational age, difference in patient characteristics in each study, difference in the test method, and component difference of blood. The use of different AKI criteria in each study could also influence the result of the best cutoff value for blood NGAL level.

Oliguria that fulfilled the urine output criteria occurred in about $12 \%$ of our AKI group. Many studies have reported that $>50 \%$ of AKI cases are nonoliguric, highlighting the insensitivity of oliguria to predict AKI in newborns ${ }^{30,31)}$. For example, ElFarghali et al. ${ }^{17)}$ reported that, of 60 full-term infants, 34 infants were found to have AKI according to the criteria proposed by the AKIN. This is consistent with our study showing a lower rate of oliguria than other studies because our AKI group was composed of infants with a milder stage of AKI.

However, the present study also has limitations. First, the diagnosis of AKI based on serum Cr level is limited by the late res. ponse of serum $\mathrm{Cr}$ to AKI. Therefore, infants with elevated plasma NGAL level before serum Cr elevation might have been missed as having neonatal AKI. El-Farghali et al. ${ }^{17)}$ reported that serum NGAL levels are significantly increased in neonates with evolving AKI before serum Cr elevation, and that serum NGAL levels are significantly correlated with subsequent serum $\mathrm{Cr}$ levels, not the initial serum Cr levels. Second, this study was performed at a single center, thus limiting the number of the enrolled newborn infants with AKI. Therefore, a large multicenter randomized trial on the clinical application of plasma NGAL for newborn infants with AKI is needed. Further investigations with larger patient groups are also required to better assess the role of rapid plasma NGAL assay for AKI diagnosis in critically ill newborn infants at bedside. Third, to verify a better biomarker for AKI, simultaneous examination of other serum biomarkers is desirable ${ }^{24,32)}$. Recent studies have unveiled other AKI biomarkers including interleukin-18 ${ }^{14)}$ and cystatin $\mathrm{C}^{15)}$. Fourth, our study could not evaluate the power of NGAL level to diagnose AKI before serum Cr level owing to the limitation of the retrospective chart review. Therefore, a prospective study with a larger group should be performed in the future with serial NGAL and serum Cr tests for critically ill newborn infants who are likely to develop AKI.

In conclusion, the rapid plasma NGAL assay has diagnostic value for AKI in critically ill newborn infants $>34$ weeks of gestational age. Further investigations with a larger population are needed to confirm the potential application of plasma NGAL level for diagnosing and managing AKI in newborn infants.

\section{ACKNOWLEDGEMENT}

We thank the physicians and nursing staff working in the neonatal intensive care unit of Korea University Ansan Hospital for their enthusiastic support and cooperation.

\section{REFERENCES}

1) Schrier RW, Wang W, Poole B, Mitra A. Acute renal failure: definitions, diagnosis, pathogenesis, and therapy. J Clin Invest 2004;114:5-14.

2) Timovska SN, Cekovska S, Tosheska-Trajkovska K. Acute kidney injury in newborns. Pril (Makedon Akad Nauk Umet Odd Med Nauki) 2015;36:83-9.

3) Abitbol CL, Bauer CR, Montane B, Chandar J, Duara S, Zilleru- 
elo G. Long-term follow-up of extremely low birth weight infants with neonatal renal failure. Pediatr Nephrol 2003;18:887-93.

4) Cuzzolin L, Fanos V, Pinna B, di Marzio M, Perin M, Tramontozzi $\mathrm{P}$, et al. Postnatal renal function in preterm newborns: a role of diseases, drugs and therapeutic interventions. Pediatr Nephrol 2006;21:931-8.

5) Ramasethu J. Complications of vascular catheters in the neonatal intensive care unit. Clin Perinatol 2008;35:199-222.

6) Koralkar R, Ambalavanan N, Levitan EB, McGwin G, Goldstein $\mathrm{S}$, Askenazi D. Acute kidney injury reduces survival in very low birth weight infants. Pediatr Res 2011;69:354-8.

7) Selewski DT, Cornell TT, Heung M, Troost JP, Ehrmann BJ, Lombel RM, et al. Validation of the KDIGO acute kidney injury criteria in a pediatric critical care population. Intensive Care Med 2014;40:1481-8.

8) Atiyeh BA, Dabbagh SS, Gruskin AB. Evaluation of renal function during childhood. Pediatr Rev 1996;17:175-80.

9) Abrahamson DR. Glomerulogenesis in the developing kidney. Semin Nephrol 1994;11:375-89.

10) Askenazi DJ, Ambalavanan N, Goldstein SL. Acute kidney injury in critically ill newborns: what do we know? What do we need to learn? Pediatr Nephrol 2009;24:265-74.

11) Goldstein SL. Kidney function assessment in the critically ill child: is it time to leave creatinine behind? Crit Care 2007;11:141.

12) Genc G, Ozkaya O, Avci B, Aygun C, Kucukoduk S. Kidney injury molecule-1 as a promising biomarker for acute kidney injury in premature babies. Am J Perinatol 2013;30:245-52.

13) Sarafidis K, Tsepkentzi E, Agakidou E, Diamanti E, Taparkou A, Soubasi V, et al. Serum and urine acute kidney injury biomarkers in asphyxiated neonates. Pediatr Nephrol 2012;27:1575-82.

14) Unal E, Ozen A, Boysan E, Tak S, Basar V, Soran Turkcan B, et al. Serum interleukin-18 as an early marker of acute kidney injury following open heart surgery. Turk Gogus Kalp Dama 2014; 22:483-8.

15) Krawczeski CD, Vandevoorde RG, Kathman T, Bennett MR, Woo JG, Wang Y, et al. Serum cystatin $\mathrm{C}$ is an early predictive biomarker of acute kidney injury after pediatric cardiopulmonary bypass. Clin J Am Soc Nephrol 2010;5:1552-7.

16) Mishra J, Ma Q, Prada A, Mitsnefes M, Zahedi K, Yang J, et al. Identification of neutrophil gelatinase-associated lipocalin as a novel early urinary biomarker for ischemic renal injury. J Am Soc Nephrol 2003;14:2534-43.

17) El-Farghali OG, El-Raggal NM, Mahmoud NH, Zaina GA. Serum neutrophil gelatinase-associated lipocalin as a predictor of acute kidney injury in critically-ill neonates. Pak J Biol Sci 2012;15:231-7.

18) Zappitelli M, Washburn KK, Arikan AA, Loftis L, Ma Q, Devarajan $P$, et al. Urine neutrophil gelatinase-associated lipocalin is an early marker of acute kidney injury in critically ill children: a prospective cohort study. Crit Care 2007;11:R84.

19) Nickolas TL, O'Rourke MJ, Yang J, Sise ME, Canetta PA, Barasch $\mathrm{N}$, et al. Sensitivity and specificity of a single emergency department measurement of urinary neutrophil gelatinase-associated lipocalin for diagnosing acute kidney injury. Ann Intern Med 2008;148:810-9.

20) Krawczeski CD, Woo JG, Wang Y, Bennett MR, Ma Q, Devarajan P. Neutrophil gelatinase-associated lipocalin concentrations predict development of acute kidney injury in neonates and children after cardiopulmonary bypass. J Pediatr 2011;158:100915.el.

21) Askenazi DJ, Montesanti A, Hunley H, Koralkar R, Pawar P, Shuaib F, et al. Urine biomarkers predict acute kidney injury and mortality in very low birth weight infants. J Pediatr 2011;159: 907-12.e1.

22) Raggal NE, Khafagy SM, Mahmoud NH, Beltagy SE. Serum neutrophil gelatinase-associated lipocalin as a marker of acute kidney injury in asphyxiated neonates. Indian Pediatr 2013;50: 459-62.

23) Selewski DT, Jordan BK, Askenazi DJ, Dechert RE, Sarkar S. Acute kidney injury in asphyxiated newborns treated with therapeutic hypothermia. J Pediatr 2013;162:725-9.

24) Selewski DT, Charlton JR, Jetton JG, Guillet R, Mhanna MJ, Askenazi DJ, et al. Neonatal acute kidney injury. Pediatrics 2015; 136:e463-73.

25) Herget-Rosenthal S, Marggraf G, Hüsing J, Göring F, Pietruck F, Janssen $\mathrm{O}$, et al. Early detection of acute renal failure by serum cystatin C. Kidney Int 2004;66:1115-22.

26) Gallini F, Maggio L, Romagnoli C, Marrocco G, Tortorolo G. Progression of renal function in preterm neonates with gestational age $\leq 32$ weeks. Pediatr Nephrol 2000;15:119-24.

27) Uttenthal LO. NGAL: a marker molecule for the distressed kid ney. Clin Lab Int 2005;29:39-41.

28) Jiang L, Cui H. Could blood neutrophil gelatinase-associated lipocalin (NGAL) be a diagnostic marker for acute kidney injury in neonates? A systemic review and meta-analysis. Clin Lab 2015;61:1815-20.

29) Baumert M, Surmiak P, Więcek A, Walencka Z. Serum NGAL and copeptin levels as predictors of acute kidney injury in asphyxiated neonates. Clin Exp Nephrol 2017;21:658-64.

30) Aggarwal A, Kumar P, Chowdhary G, Majumdar S, Narang A. Evaluation of renal functions in asphyxiated newborns. J Trop Pediatr 2005;51:295-9.

31) Gupta B, Sharma P, Bagla J, Parakh M, Soni J. Renal failure in asphyxiated neonates. Indian Pediatr 2005;42:928-34.

32) Bellomo R, Kellum JA, Ronco C. Acute kidney injury. Lancet 2012;380:756-66. 